\title{
Effect of biostimulants on grafted and self-rooted eggplant (Solanum melongena L.)
}

\author{
Noémi KAPPEL ${ }^{1}$ - Maryam MOZAFARIAN ${ }^{1}$ - Nicoló VELA² - Attila OMBÓDI ${ }^{3}$ - \\ Claudio Kendi MORIKAWA ${ }^{4}$ \\ 1: Szent István University, Department of Vegetable and Mushroom Growing \& Hungary, 1118 Budapest, \\ Villányi út 29-43.; E-mail: kappel.noemi@kertk.szie.hu \\ 2: Bologna University, Faculty of Agricultural Science \& Italy, 40126 Bologna Via Zamboni 33; E-mail: \\ nicolo.vela@studio.unibo.it \\ 3: Szent István University, Faculty of Agricultural and Environmental Sciences \& Hungary, 2100 Gödöllö, \\ Páter K. utca 1.; E-mail: ombodi.attila@mkk.szie.hu \\ 4: Institute of Vegetable and Floricultural Science, Quality and Function Research Unit \& 360 Kusawa, Anou, \\ Tsu, Mie 514-2392, Japan E-mail: ckm@affrc.go.jp
}

Keywords: eggplant, grafting

\section{Introduction}

The cultivation of grafted vegetable is among the essential horticultural techniques for in many parts of the world, where intensive cropping is routinely practiced. Improvement of nutrient uptake, secondary metabolites production, enhancement of chlorophyll content are just some of the ways both grafting and biostimulants can interfere with plant physiology. As a result, plants appear to be more resistant to both biotic and abiotic stresses, healthier, resulting also in an increase in terms of yield production (Colla et al. 2017). The aim of this work was to take into consideration both grafting technology, through the use of grafted eggplant and two biostimulants, taking part to the experimental trials fundamental for the development of a more sustainable production system.

\section{Materials and methods}

The experiment took place in the farm of Szent István University of Budapest, in the area of Soroksár. Two biostimulants, produced by Intermag company were used. The first product called Optysil is composed by $24 \mathrm{~g} / 1$ of Iron $(\mathrm{Fe})$ and $200 \mathrm{~g} / 1$ Silicon dioxide $\left(\mathrm{SiO}_{2}\right)$. The other product Tytanit contains $62 \mathrm{~g} / \mathrm{l}$ of Magnesium oxide $(\mathrm{MgO}), 124 \mathrm{~g} / \mathrm{l}$, Sulphur trioxide $\left(\mathrm{SO}_{3}\right)$ and $8,5 \mathrm{~g} / 1$ of Titanium (Ti). As test plant self-rooted eggplant (variety: 'Madonna' from Monsanto) and grafted eggplant (rootstock: Taybio (Solanum grandifolium x Solanum melongena) from Takii Seed) were used. The seedlings (grafted and non grafted ones) were produced under heated plastic tunnel. Planting date was on $30^{\text {th }}$ of May 2017 in open field condition (black plastic mulch covering with drip-irrigation). The research area was divided in 4 rows with $80 \mathrm{~cm}$ distance and $60 \mathrm{~cm}$ distance between the plants inside the rows. Self-rooted and grafted plants were planted out in 4 replicates in randomised block design, with 15 plants in each replicates. From the 15 plants 5-5 were treated with the two biostimulants and 5 untreated plants were the control. The application of the biostimulants was performed two times, first after planting and second time after 3 weeks of planting. The parameters that have been measured during the experiment were: height of the plant $(\mathrm{cm})$, photosynthetic activity (measured with SPAD-502 Plus equipment), yield (kg/plant) and fruit composition: ascorbic acid, gallic acid (FRAP analysis); microelement content: iron, silicon and titanium (ICP analysis). The collected data statistically were studied in different ways, according to the correlation to prove (two- 
way analysis of variance, if the results were given a certain significance, then the analysis went on with the LSD (Least Significant Difference) test.

\section{Results and discussion}

By the total yield the use of the biostimulants (no difference between the two types) lead to an increase of production, without any meaningful correlation with grafting (control plants $6,61 \mathrm{~kg} /$ plant, with Optysil 8,07 kg/plant, with Tytanit 8,78 kg/plant). On plants where Optysil was applied, the yield increased and the difference between the self-rooted and grafted plants decreased; in the case of Tytanit, grafted plants gave more yield than the self-rooted ones. The final stem length of the control plants ranges between $95,8 \mathrm{~cm}$ (grafted plants) and 122,47 cm (self-rooted). Grafting resulted more chlorophyll content in the plants comparing to self-rooted ones. These differences become more meaningful towards the end of the season. In self-rooted varieties the application of biostimulants contributed to the increase of Ascorbic Acid content. In particular, the plants on which Optysil was applied, show the highest values: $23,32 \mathrm{microMol} / \mathrm{g}$ for the peel and 9,18 for the pulp. In general, both the grafted and the self-rooted plants show the same differences in fruit composition, end generally the self-rooted ones contain higher amount of the measured microelements than the grafted plants. This trend followed the one registered by Tomohito et al. (2008), when they noticed how self-rooted eggplants tended to absorb more Cadmium than grafted ones.

\section{Conclusions}

Our study was useful to have consequences of the combined use of grafting technique and specific biostimulants growing eggplant in open field condition. Our results showed that the use of grafting with the tested scion-rootstock combination and even the use of the two biostimulants lead to an increase of yield and photosynthetic activity. Also considering the review literature, the wish is to proceed with further studies and researches to develop both the use of grafting and the biostimulants in agriculture, which is clear that could lead to an improvement of quality and quantity in production, in a period in which the environmental respect must be considered as an absolute priority.

\section{Acknowledgement}

This research was partially supported by TÉT-16-1-2016-0203 project.

\section{References}

Colla G., Perez-Alfocea F. Schwarz D. (2017): Vegetable grafting: Principles and practices. 296. Publisher Wallingford, Oxfordshire, UK ; Boston, MA, USA : CABI ISBN-10: 1780648979, ISBN-13: 978-1780648972

Tomohito A., Hiroyuki T., Eiji N. (2008): Reduction of Cadmium Translocation from Roots to Shoots in Eggplant (Solanum melongena) by Grafting onto Solanum torvum Rootstock. Soil Science and Plant Nutrition 54:4. 555-559. https://doi.org/10.1111/j.1747-0765.2008.00269.x 